\title{
A rare case of bullous congenital ichthyosiform erythroderma in a newborn
}

\author{
Thumjaa Annamalai ${ }^{1}$, Vamsikrishna Reddy Kandriga ${ }^{2}$, Sindhu maru $^{3}$ \\ ${ }^{1}$ Dr Thumjaa Annamalai, M.D (Paediatrics), Assistant Professor, ${ }^{2}$ Dr Vamsikrishna Reddy kandriga, Post graduate, ${ }^{3}$ Dr \\ Sindhu maru, Post graduate, All are affiliated with Department of Paediatrics, Sree Balaji Medical College and Hospital, \\ Chennai, Tamil Nadu, India.
}

Address for Correspondence: Department of Paediatrics, Sree Balaji Medical College and Hospital Chennai, Tamil Nadu, India

\begin{abstract}
Bullous congenital ichthyosiform erythroderma is a rare disorder of keratinization. It is associated with defective keratinization leading to skin fragility, blistering and hyperkeratosis. This condition was difficult to distinguish from staphylococcal scalded skin syndrome. We report a case of Bullous congenital ichthyosiform erythroderma in a 72 hour old male baby and discussed the differential diagnosis and management of the disease.
\end{abstract}

Keywords: Bullous Congenital ichthyosiform erythroderma, Keratinization disorder .

\section{Introduction}

Bullous congenital ichthyosiform erythroderma is a rare disorder of keratinization, it is also known as epidermolytic hyperkeratosis [1]. It is a rare autosomal dominant trait with a prevalence of 1 case per 200000 to 300000 individuals [2]. Bullous congenital ichthyosiform erythroderma is caused by mutations in keratin1 or keratin $10[3,4]$. These keratins are expressed in the differential spinous and granular layers of the epidermis, which are the sites of disease [2].

Bullous congenital ichthyosiform erythroderma typically occurs in newborns they present with generalized erythroderma , characterized by erythema and scaling with or without edema[5]. The blistering and erythema often improve overtime. Hyperkeratotic scale becomes more prominent mostly over the neck, hand, feet and joints. Bullous congenital ichthyosiform erythroderma skin disorder persists throughout the lifetime of the patient.

Here with we present a rare case in a newborn with Bullous congenital ichthyosiform erythroderma and to describe how the final diagnosis was obtained.

Manuscript received: $26^{\text {th }}$ Dec 2015

Reviewed: $05^{\text {th }}$ Jan 2016

Author Corrected; $14^{\text {th }}$ Jan 2016

Accepted for Publication: $25^{\text {th }}$ Jan 2016

\section{Case Presentation}

A 72 hour old male baby with multiple erosions in post natal ward at Sree Balaji Medical College and hospital, he was born by caesarean section, term baby with birth weight of $3.2 \mathrm{~kg}$ without any complications till 72 hours of life, later baby developed blisters and erosions on the hand then to abdomen as shown in picture (1) back , thighs and soles. There was history of bullous ichthyosiform disease in his sibling, physical examination showed, baby was afebrile, with multiple superficial erosions over the entire body and bullae over the hand has shown in the picture (2) fine scaly lesions was present over the face and chest as shown in the picture (3) and back. Blood cell counts were within normal limits.

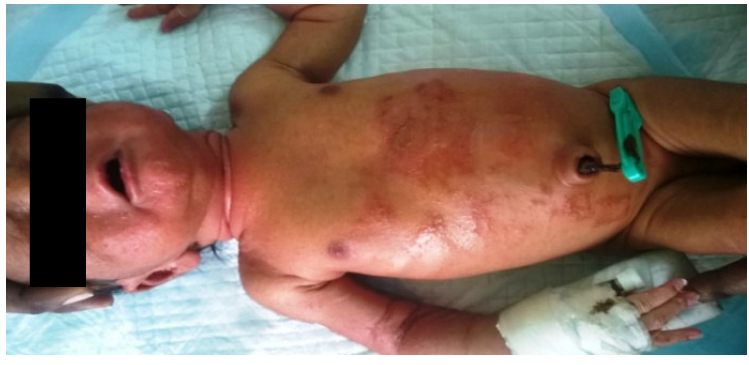

Picture 1 -Blisters and multiple erosions over the abdomen 
Based on his clinical presentation of generalized blisters with multiple erosions, fine scaling and erythematous lesions, baby was clinically diagnosed as Bullous congenital ichthyosiform erythroderma and was treated with topical emollients.

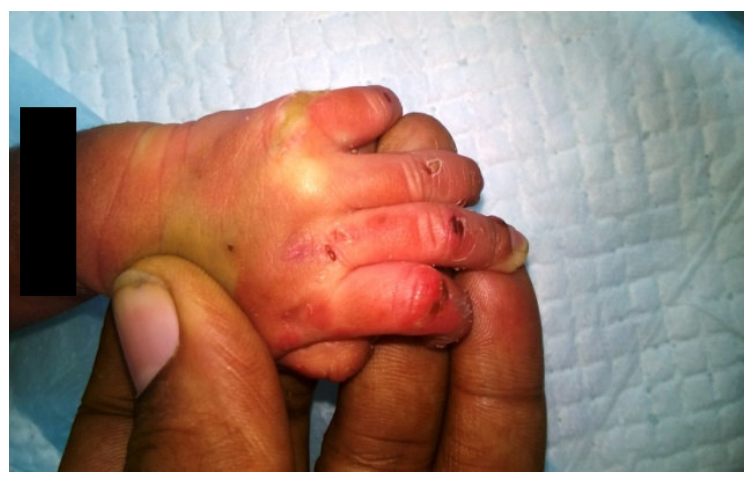

Picture 2: Multiple erosions with bullae in hand

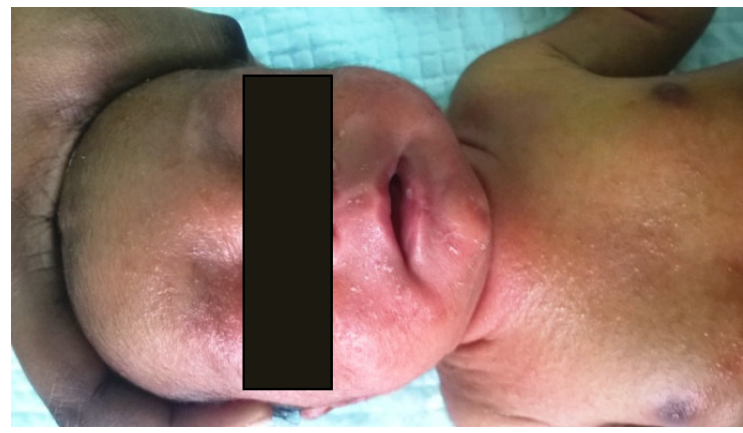

Picture 3: Fine scaly lesion over the face

\section{Discussion}

Bullous congenital ichthyosiform erythroderma is a congenital form of icthiosis that causes disturbance of epithelial layer which may lead to severe infection and sepsis if not identified and controlled. It is a rare autosomal dominant disorder of keratinization that starts at birth ${ }^{1}$.

The newborn with blisters is important to rule out differential diagnosis mainly staphylococcal scalded skin syndrome, which is a toxin mediated skin condition that presents with blistering and wide spread erythema and exfoliation.

However this baby had no signs of infection with normal vital signs and normal interaction with the mother. The fine scaling which was present in the face, neck and back was an important clue which supported as an ichthyotic etiology over staphylococcal scalded skin syndrome. Histologically Bullous congenital ichthyosiform erythroderma shows epidermolytic hyperkeratosis characterized by acanthuses, prominent keratohyaline granules, eosinophilic globules and perinuclear bands [6,7], perinuclear vacuoles and hyperkeratosis with ballooning degeneration of the granular and spinous layers of the epidermis [2].

In contrast staphylococcal scalded skin syndrome is characterized by non-inflammatory, non-epidermolytic, intra epidermal acantholytic cleavage plane restricted to the granular cell layer. Bullous congenital ichthyosiform erythroderma, treated conservatively with the use of topical emollients which is considered as mainstay therapy. As well as creams and ointments they possess keratolytic properties to reduce the hyperkeratosis scale that develop in these patients [8].

\section{Conclusion}

Bullous congenital ichthyosiform erythroderma is rare and has a challenging differential diagnosis it is important for clinicians to identify the disease in order to reduce morbidity and mortality.

\section{References}

1. Brocq L. Erythrodermie congenital ichthyosiforme avec hyperepidermotrophie.Ann Dermatol Syphiligr. 1902;vol 4:pg [1-31].

2. DiGiovanna JJ, Bale SJ. Clinical heterogeneity in epidermolytic hyperkeratosis. Arch Dermatol. 1994 Aug;130(8):1026-35.

3. Cheng J, Syder AJ, Yu QC, Letai A, Paller AS, Fuchs E. The genetic basis of epidermolytic hyperkeratosis: a disorder of differentiation-specific epidermal keratin genes. Cell. 1992;vol 70:[ 811-819].

4. Chipev $\mathrm{CC}^{1}$, Korge $\mathrm{BP}$, Markova $\mathrm{N}$, Bale SJ, DiGiovanna JJ, Compton JG, Steinert PM. A leucine----proline mutation in the $\mathrm{H} 1$ subdomain of keratin 1 causes epidermolytic hyperkeratosis. Cell. 1992 Sep 4;70(5):821-8.

5. Kwak J, Maverakis E. Epidermolytic hyperkeratosis. Dermatol Online J. 2006 Sep 8;12(5):6.

6. El Shabrawi-Caelen L, McCalmont TH. Perinuclear eosinophilic bands: a clue to keratin gene mutation. J Cutan Pathol. 2010 Jul;37(7):718-9. doi: 10.1111/j.1600-0560.2010.01555.x.

7. Bergman R, Khamaysi Z, Sprecher E. A unique pattern of dyskeratosis characterizes epidermolytic 
hyperkeratosis and epidermolytic palmoplantar

keratoderma. Am J Dermatopathol. 2008; vol 30: $\operatorname{pg}[101-105]$.

8. Kempers S, Katz HI, Wildnauer R, Green B. An evaluation of the effect of an alpha hydroxy acid-blend skin cream in the cosmetic improvement of symptoms of moderate to severe xerosis, epidermolytic hyperkeratosis, and ichthyosis. Cutis. 1998; vol 61:pg [347-350].

\section{How to cite this article?}

Thumjaa Annamalai, Vamsikrishna Reddy Kandriga, Sindhu maru A rare case of bullous congenital ichthyosiform erythroderma in a newborn.Pediatr Rev: Int J Pediatr Res 2016;3(1):77-79.doi:10.17511/ijpr.2016.i01.15 